\title{
Regioselective Ring Opening of Enantiomerically Enriched Epoxides via Catalysis with Chiral (Salen)Cr(III) Complexes
}

\author{
Bridget D. Brandes, Eric N. Jacobsen* \\ Department of Chemistry and Chemical Biology, Harvard University, Cambridge, Massachusetts 02138, USA \\ Fax (617) 496-1880 \\ Received 2 February 2001 \\ Dedicated with respect and admiration to Professor Ryoji Noyori.
}

\begin{abstract}
Chiral (salen)chromium(III)N $\mathrm{N}_{3}$ complexes are demonstrated to be catalysts for the regioselective ring opening a variety of enantiomerically enriched epoxides. Selective nucleophilic attack at either epoxide carbon atom can be achieved by selection of the appropriate enantiomer of catalyst. A highly selective synthesis of norpseudoephedrine is described using this strategy.
\end{abstract}

Key words: regioselectivity, ring opening, (salen)Cr(III) complexes, epoxides

While the principal application of asymmetric catalysis is clearly toward enantioselective or diastereoselective reactions, the possibility also exists for a chiral catalyst to exert regiochemical control on a chiral substrate. This effect has been observed in a few cases in the context of parallel kinetic resolution reactions, wherein the two enantiomers of a racemate may be transformed to regioisomeric products. ${ }^{1}$ A different manifestation of the same concept can be envisaged wherein the two enantiomeric partners of a chiral catalyst effect complementary regioselectivity on an enantioenriched substrate. ${ }^{2}$ This principle is easily grasped if one considers the nucleophilic ring-opening of epoxides with a chiral catalyst (Scheme 1). Several examples have been uncovered of enantioselective nucleophilic ring-opening of meso epoxides, ${ }^{3}$ wherein catalyst enantioselectivity is manifested through selective nucleophilic attack at one of the enantiotopic C-O bonds. Naturally, the mirror-image catalyst reacts with the same selectivity at the other $\mathrm{C}-\mathrm{O}$ bond, leading to the enantiomeric product in identical ee. In the case of an enantioenriched chiral epoxide wherein the heterotopic $\mathrm{C}-\mathrm{O}$ bonds might be considered pseudo-enantiotopic, the same selectivity principles could result in enantiomeric catalysts affording regiocomplementary products. Such a process would constitute a peculiar example of "double asymmetric synthesis," 4 and on a practical level could define a novel strategy for effecting regioselective reactions of sterically and electronically unbiased substrates. We have explored this idea in the context of the (salen)Cr-catalyzed addition of $\mathrm{TMSN}_{3}$ to epoxides, ${ }^{5}$ and describe our results herein.

Enantiomerically enriched cis dialkyl substituted epoxides, such as cis-2-heptene oxide and cis-2-octene oxide (3 and 4) bearing what may be viewed as "pseudoenantiotopic" C-O bonds, were evaluated first for regioselective epoxide ring opening in the (salen) $\mathrm{CrN}_{3}-$ catalyzed asymmetric ring opening (ARO) reaction. The
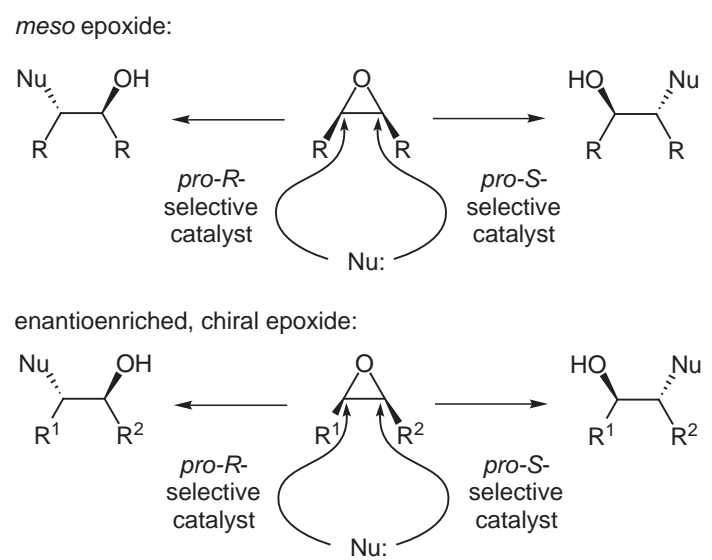

Scheme 1

enantioenriched epoxides were accessed by asymmetric epoxidation of the corresponding alkenes catalyzed by the enzyme chloroperoxidase using hydrogen peroxide. ${ }^{6}$ The achiral (salen) $\mathrm{CrN}_{3}$ catalyst (1) effected ring-opening of $(2 R, 3 S)-\mathbf{3}$ and $(2 R, 3 S)-\mathbf{4}$ with no measurable regioselectivity, affording the ring-opened products in a 1:1 ratio (Table). Ring-opening with catalyst $(R, R)-2$ provided a modest 2:1 regioselectivity, while use of the enantiomeric $(S, S)$-2 led to a reversal in selectivity in both cases to afford a 1:4 and 1:3 ratio of regioisomers. Thus, while chiral (salen) $\mathrm{CrN}_{3}$ catalyst 2 exerted only marginal control over the regioselectivity of epoxide ring opening, these examples provided a clear proof-of-principle of the desired effect.

More significant levels of catalyst control were revealed in the ring opening of styrene oxide derivatives. Three enantioenriched epoxides, $(R)$-styrene oxide $(\mathbf{5})$, cis- $\beta$ methylstyrene oxide (6), and trans- $\beta$-methylstyrene oxide (7) were examined. ${ }^{8}$ Epoxides 5 and $\mathbf{7}$ were obtained in highly enantiomerically enriched form ( $>99 \%$ ee) from commercial sources. ${ }^{9}$ Epoxide $\mathbf{6}$ was synthesized by asymmetric epoxidation using the previously reported low temperature conditions with (salen) $\mathrm{MnCl}$ catalysts. ${ }^{10}$

Treatment of $(R)$-styrene oxide (5) with $5 \mathrm{~mol} \%$ achiral catalyst 1 and $\mathrm{Me}_{3} \mathrm{SiN}_{3}$ at $20{ }^{\circ} \mathrm{C}$, afforded a 4:1 ratio of regioisomeric products with preferential azide attack at the less hindered $\beta$-terminal position. Use of the chiral catalyst $(S, S)$-2 enhanced the substrate bias to provide an 18:1 ratio of products favoring $\beta$-substitution. The enantiomer- 
Table Asymmetric Ring Opening (ARO) of Enantiomerically Enriched Epoxides. ${ }^{7}$

\begin{tabular}{|c|c|c|c|}
\hline Entry & Epoxide & $\begin{array}{l}\text { Catalyst }^{n} \\
(0.13 \mathrm{M})\end{array}$ & $\begin{array}{l}\text { Regioselectivity } \\
\text { (Time, Yield }^{b} \text { ) }\end{array}$ \\
\hline 1 & $\begin{array}{c}\mathrm{H}_{3} \mathrm{C} \mathrm{b}_{n-\mathrm{C}_{4} \mathrm{H}_{9}} \\
\mathbf{3}(95 \% \mathrm{ce})\end{array}$ & $\begin{array}{c}1 \\
(R, R)-\mathbf{2} \\
(S, S)-\mathbf{2} \\
\end{array}$ & $\begin{array}{l}1: 1(44 \mathrm{~h}, 81) \\
2: 1(26 \mathrm{~h}, 79) \\
1: 4(15 \mathrm{~h}, 77)\end{array}$ \\
\hline 2 & $\begin{array}{c}\mathrm{H}_{3} \mathrm{C} \mathrm{b}_{n-\mathrm{C}_{5} \mathrm{H}_{14}} \\
\mathbf{4}(88 \% \text { ee })\end{array}$ & $\begin{array}{c}1 \\
(R, R)-2 \\
(S, S)-\mathbf{2} \\
\end{array}$ & $\begin{array}{l}1: 1(44 \mathrm{~h}, 73) \\
2: 1(23 \mathrm{~h}, 74) \\
1: 4(15 \mathrm{~h}, 71)\end{array}$ \\
\hline 3 & $\underset{\mathrm{a} \mathrm{b}_{\mathrm{Ph}}}{\mathrm{S}_{\mathrm{P}}(>99 \% \text { ee })}$ & $\begin{array}{c}1 \\
(R, R)-2 \\
(S, S)-2\end{array}$ & $\begin{array}{c}4: 1(16 \mathrm{~h}, 88) \\
1: 7(23 \mathrm{~h}, 87) \\
18: 1(21 \mathrm{~h}, 87)\end{array}$ \\
\hline 4 & $\begin{array}{l}\mathrm{H}_{3} \mathrm{C}^{\mathrm{a}} \mathrm{bh} \\
\mathbf{6}(98 \% \text { ee })\end{array}$ & $\begin{array}{c}1 \\
(R, R)-2 \\
(S, S)-2\end{array}$ & $\begin{array}{c}3: 1(30 \mathrm{~h}, 73) \\
1: 4(20 \mathrm{~h}, 85) \\
45: 1(27 \mathrm{~h}, 70)\end{array}$ \\
\hline 5 & 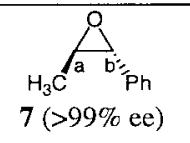 & $\begin{array}{c}1 \\
(R, R)-2 \\
(S, S)-2\end{array}$ & $\begin{array}{c}1: 9(16 \mathrm{~h}, 89) \\
1: 1(32 \mathrm{~h}, 85) \\
1: 84(16 \mathrm{~h}, 88)\end{array}$ \\
\hline
\end{tabular}

${ }^{a}$ Catalyst concentrations were $0.12-0.13 \mathrm{M}$ for substrates 5-7, and 0.06-0.08 $\mathrm{M}$ for 3 and $4 .{ }^{b}$ Selectivities are expressed as the ratio of products resulting from azide attack at positions a and $b(a: b)$. Ratios were determined by GC analysis for styrene oxide and its derivatives, and by ${ }^{1} \mathrm{H}$ NMR for the aliphatic substrates. ${ }^{c}$ Isolated yield of the regioisomeric mixture.

ic catalyst, $(R, R)-\mathbf{2}$, overrode the substrate bias to afford a $1: 7$ ratio of products, the major isomer resulting from azide attack at the $\alpha$-benzylic carbon atom. The enantiopurity of the two product regioisomers in the epoxide ring opening of $\mathbf{5}$ was conserved as determined by chiral gas chromatographic analysis.

The ring opening of cis-and trans- $\beta$-methylstyrene oxide $(6$ and 7$)$ revealed similar profound matched and mismatched effects with 2 (Table, entries 4-5). In the case of 6, the $3: 1$ substrate bias for $\beta$-substitution could be overcome to afford the $\alpha$-benzylic substituted product, albeit with moderate 1:4 selectivity. The regioselectivity with trans-disubstituted 7 was 1:9 for $\alpha$-benzylic substitution using achiral catalyst $\mathbf{1}$, and the mismatched catalyst $(R, R)-\mathbf{2}$ effectively nullified this inherent bias to afford a 1:1 ratio of products. The tendency for cis- and trans-styrene oxide derivatives to display opposite regioselectivity in nucleophilic attack is well-documented, and may be explained by considering the difference in the stereoelectronic properties of the two disubstituted epoxides. ${ }^{11}$ In cis-epoxide 6, the phenyl group is rotated to avoid steric interactions with the methyl group, with the effect of blocking nucleophilic attack at the benzylic center. In contrast, the phenyl group of trans epoxide 7 is not subject to such a steric interaction and thus attack at the more electrophilic benzylic carbon atom is favored.

The new methodology was applied in a straightforward manner to the synthesis of $(1 S, 2 S)$-norpseudoephedrine (8), a naturally occurring anorexiant found in several plant species. $^{12}$ Sequential asymmetric epoxidation of $\operatorname{cis}$ - $\beta$ methylstyrene, selective ring opening as described above, and chromatographic purification afforded regioisomerically pure product in $51 \%$ overall yield. Azide reduction with $\mathrm{LiAlH}_{4}$ provided $\mathbf{8}$ cleanly and in $>99 \%$ ee.

(1S,2R)-6
$\begin{gathered}\text { 18:1 cis/trans } \\ 98 \% \text { ee } \\ \text { (cis isomer) }\end{gathered}$

Scheme 2 Synthesis of norpseudoephedrine (8).

\section{Acknowledgement}

This work was supported by the National Institutes of Health (GM43214) and by an Eli Lilly \& Company-sponsored ACS Organic Division Graduate Fellowship to B. D. B.

\section{References and Notes}

(1) For reviews, see: (a) Kagan, H. B. Croat. Chem. Acta 1996, 69, 669-680. (b) Eames, J. Angew. Chem. Int. Ed. 2000, 39, 885-888.

(2) von Matt, P.; Lloyd-Jones, G. C.; Minidis, A. B. E.; Pfaltz, A.; Macko, L.; Neuburger, M.; Zehnder, M.; Rüegger, H.; Pregosin, P. S. Helv. Chim. Acta 1995, 78, 265-284.

(3) For reviews, see: (a) Hodgson, D. M.; Gibbs, A. R.; Lee, G. P. Tetrahedron 1996, 52, 14361-14384. (b) Jacobsen, E. N.; Wu, M. H. in Comprehensive Asymmetric Catalysis, Jacobsen, E. N.; Pfaltz, A.; Yamamoto, H., Eds.; Springer: New York; 1999, Chapter 35.

(4) Masamune, S.; Choy, W.; Petersen, J. S.; Sita, L. R. Angew. Chem. Int. Ed. Engl. 1985, 24, 1-30.

(5) (a) Martínez, L. E.; Leighton, J. L.; Carsten, D.; Jacobsen, E. J. J. Am. Chem. Soc. 1995, 117, 5897-5898. (b) Schaus, S. E.; Larrow, J. F.; Jacobsen, E. N. J. Org. Chem. 1997, 62, 41974199. (c) Jacobsen, E. N. Acc. Chem. Res. 2000, 33, 421-431.

(6) Allain, E. J.; Hager, L. P.; Deng, L.; Jacobsen, E. N. J. Am. Chem. Soc. 1993, 115, 4415-4416.

(7) CAUTION!: These experiments have proceeded without incident, but extreme caution should be exercised in the handling of organic and metal azides. Experimental procedure: A 10-mL, oven-dried, round-bottomed flask equipped with a magnetic stirbar and air-free adapter was charged with catalyst $(5 \mathrm{~mol} \%, 0.13 \mathrm{M})$, tert-butyl methyl ether (TBME), and epoxide under nitrogen and then cooled to the appropriate temperature (thermostatted isopropanol bath). Azidotrimethylsilane (1.1 equiv) was added via syringe until the mixture became homogenous. The reaction mixture was then stirred under nitrogen until completion, then TBME and excess $\mathrm{Me}_{3} \mathrm{SiN}_{3}$ were removed. The residue was purified by flash column chromatography eluting with 2.5-10\% EtOAc in pentane or $5-25 \% \mathrm{CH}_{2} \mathrm{Cl}_{2}$ in pentane to yield the mixture of azidotrimethylsilyl ethers.

(8) The regioselective addition of azide to racemic styrene oxide derivatives has been reported, but these reactions do not proceed stereospecifically when applied to enantiomerically enriched substrates. (a) Sutowardoyo, K. I.; Emziane, M.; Lhoste, P.; Sinou, D. Tetrahedron 1991, 47, 1435-1446. (b) Morrison, J. D.; Atkins, R. L.; Tomaszewski, J. E. Tetrahedron Lett. 1970, 4635-4638. 
(9) Terminal epoxides such as styrene oxide are also readily accessible in enantiopure form through the hydrolytic kinetic resolution reaction. See: Tokunaga, M.; Larrow, J. F.;

Kakiuchi, F.; Jacobsen, E. N. Science 1997, 277, 936-938.

(10) Palucki, M. P.; McCormick, G. J.; Jacobsen, E. N. Tetrahedron Lett. 1995, 36, 5457-5460.

(11) For conformational analysis of $c$ is- and trans- $\beta$-methylstyrene oxide, see: Brown, H. C.; Narasimhan, S.; Somayaji, V. J. Org. Chem. 1983, 48, 3091-3096.
(12) The Merck Index; Budavari, S., Ed.; Merck \& Co.: Rahway, 1996; no 6811.

Article Identifier:

1437-2096,E;2001,0,SI,1013,1015,ftx,en;Y04401ST.pdf 